ceived and analysed by the experimenters in virtually real time. Professor Albert Galeev provided a running commentary, doing his best to interpret data as they appeared and succeeding reasonably well except when the projectionists switched displays in the middle of a sentence. (A Hungarian image processor says he had not been asked to provide this frill until a month ago.) It is an interesting and moving experience to see mass spectrograms of the products of the impact of single cometary dust particles on a silver target literally before the West Germans who built this ingenious apparatus had a chance to censor them.

Formally, the six-day symposium was a meeting of the inter-agency coordinating group bringing together the US and European space agencies, an amalgam of the two agencies in Japan and that from the Soviet Union. Academician R.Z. Sagdeev, the driving force behind Vega and the manner of its public presentation, wanted to use the occasion for hammering out a further programme of collaboration, offering to form a working group to say what should be done next before everybody took flight for Darmstadt and the Giotto encounter. But neither NASA nor ESA was ready for this proposal, suggesting instead a formal discussion at a meeting planned for Padua in November.

Apparently there is a plan to move from Padua to Rome for a public presentation of the Halley data, including an audience with the Pope, to whom each agency is expected to provide its four best pictures of the comet, possibly on 7 November. Those making the arrangements appear to have overlooked the significance of the date, the anniversary of the October $\mathrm{Re}$ volution. Sagdeev wondered whether the Pope might be persuaded to celebrate mass for the occasion.

For the rest, the dignitaries behaved as dignitaries do on these occasions. Their congratulations have been full-throated, not merely for the success of the two Vegas but for the openness of the proceedings of which they have been a part. The institute's staff has been surprised to find the proceedings televised live from the "data analysis room", which is said to be unprecedented. But what about the Party Congress? "That's the other exception."

The good-humoured meeting has also been sadly depressed about the shuttle tragedy, wondering what the effect will be on the US space programme. NASA officials say that it has been decided to plan on the assumption that the shuttle will be operating again after a delay of twelve months, and that priority will then be given to launching the Galileo mission to Jupiter and the Hubble space telescope. The snag, it seems, is that "it's costing us $\$ 10$ million a month to keep things on hold".

John Maddox

Halley's comet

\title{
Japan's probe rocked by dust
}

\section{Tokyo}

"IT's great" was how researchers at Japan's Institute of Space and Astronautical Science (ISAS) reacted to news that their space probe Suisei (comet) had safely passed its point of closest approach to Halley's comet. Suisei was twice shaken by collision with high-velocity dust particles as it came within $150,000 \mathrm{~km}$ of the some rapid calculations as to just how big the particles must have been to rock the $135-\mathrm{kg}$ probe, bearing in mind that their relative velocity is something like $73 \mathrm{~km}$ per second. Initial estimates were that the dust weighed about $10 \mu \mathrm{g}$; but recalculation came up with a figure of $1-2 \mathrm{mg}$, giving the particles diameters of $1-2 \mathrm{~mm}$. If this proves correct it is a very big sur-

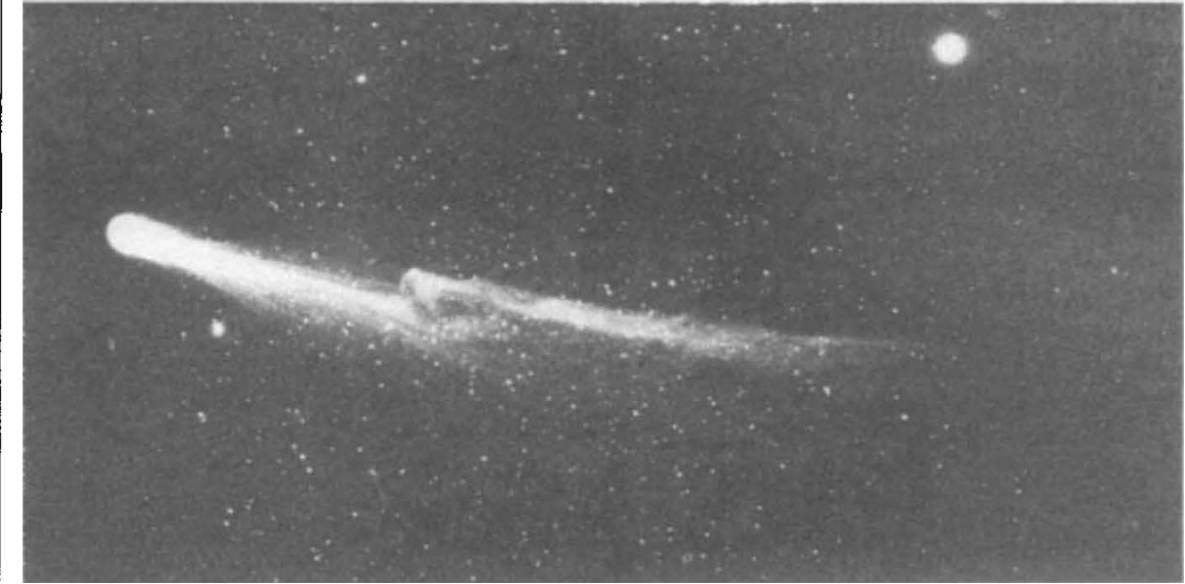

Sun side of Halley at 22.06 on Saturday, 8 March (Japan time) but in neither case was it thrown sufficiently out of orientation to affect data collection.

News of the collisions and data from the encounter did not reach Japan until Sunday, for the probe was on the wrong side of the Earth to communicate with ISAS's new deep-space observation centre at Usuda in Nagano Prefecture, west of Tokyo. Last commands sent to Suisei on Saturday were for the probe to continue to make observations with its ultraviolet camera and its ion-energy analyser according to programme. From Saturday evening until Sunday morning, signals were picked up at the US National Aeronautics and Space Administration (NASA)'s space observation centres in Spain and California, suggesting that all was going well. Then when Suisei came back round to the Japan side of the Earth, all data collected during the encounter were taken out of memory and transmitted to Japan.

The first and biggest surprise was that the probe had been shaken by collisions with dust particles just before the point of closest approach. The first collision at 20.54 knocked the rotation axis of the probe relative to the Sun out by $0.48^{\circ}$; the second at 21.26 added another $0.24^{\circ} \mathrm{de}$ viation. But neither was sufficient to affect observations of the comet. The first impact was also powerful enough to slow down the satellite's spin period of 9.184 seconds by 0.027 seconds; the second, presumably to a different part of the structure, had a scarcely noticeable effect.

News of the dust collision triggered prise and may be bad news for the European spacecraft, Giotto, which is going very much closer to Halley later this week. "We don't know whether to call it good luck or bad", said one ISAS scientist of the collisions - bad luck to have been hit or good luck to have discovered something quite unexpected; no dust particles this large were expected to be thrown off by the comet.

Not unsurprisingly, there has been no time yet to analyse data in any detail. But results from the Lyman-alpha ultraviolet imaging camera confirms the variability in the hydrogen coma of Halley's comet that the Japanese team report in this issue of Nature (see p. 140). Detailed study should make it possible to measure the period of rotation of the comet. Preliminary results from the ion-spectrum analyser also indicate that a shock-like region forms on the Sun side of the comet as the solar wind is displaced around it. Ions from the comet were detected as far as $400,000 \mathrm{~km}$ away.

Suisei will continue to make observations of Halley for as long as possible. Over the next few days, Sakigake, the test probe launched in advance of Suisei, will come into position downwind of Halley to complement its observations. On board are instruments to measure plasma waves, ion temperature, velocity and density and the interplanetary magnetic field. But scientists at ISAS are already beginning to wonder what can be done next with Suisei. One of ISAS's satellites continued to function for six years and it is hoped that further useful observations can be made with the probe as it continues to circle the Sun.

Alun Anderson 